\title{
Puerto Rico como archipiélago-experimento de emancipación contra el poder: hacia nuestros futuros decoloniales y archipelágicos ${ }^{1}$
}

\author{
Beatriz Llenín Figueroa ${ }^{2}$ \\ Universidad de Puerto Rico, \\ Recinto Universitario de Mayagüez \\ ORCID ID: 0000-0001-6782-3093
}

Recibido: 5 de mayo de 2019

Aceptado: 23 de junio de 2019

\begin{abstract}
RESUMEN
Este ensayo traza, por un lado, historias e imaginarios de conexión inter-insular entre Puerto Rico y el resto del Caribe, refutando así la ideología insularista de la carencia y el aislamiento como consecuencias "naturales" de la geografía. Por otro lado, la pesquisa figura las islas de Puerto Rico desde quienes las vivimos, las amamos y las imaginamos otras como archipiélago-experimento de emancipación contra el poder y en pos de futuros decoloniales y archipelágicos. Se ofrece un breve repaso histórico de los usos y abusos de las islas caribeñas/tropicales para beneficio del régimen capitalista colonial patriarcal y, en particular, se examina el tropo de isla-laboratorio. Luego, se resume el caso paradigmático de Puerto Rico como laboratorio del poder, culminando con una mirada a la actual intensificación de políticas del capitalismo neoliberal y del imperialismo estadounidense. Por último, se reseñan dos formas particulares de experimentación emancipadora hacia el futuro soñado: (1) la intensificación de soberanías comunitarias y (2) las posibles conexiones entre Puerto Rico, la West Indies Federation y el CARICOM.
\end{abstract}

Palabras clave: Puerto Rico, isla-laboratorio, archipiélagos, descolonización, soberanías comunitaria

\begin{abstract}
This paper outlines, on the one hand, histories and imaginaries of inter-insular connection between Puerto Rico and the rest of the Caribbean, thus refuting the insularist ideology of lack and isolation as "natural" geographical consequences. On the other, it figures the islands of Puerto Rico from the perspective of those who live, love and imagine them differently, as experiments of emancipation against power and for our decolonial and archipelagic futures. The article provides a brief historical panorama of the uses and abuses of Caribbean/tropical islands for the benefit of the capitalist-colonial-patriarchal regime and, in particular, examines the island-laboratory trope. Then, the essay summarizes the paradigmatic case of Puerto Rico as a laboratory of power, culminating
\end{abstract}

\footnotetext{
${ }^{1}$ Puerto Rico as an Emancipatory Archipelagic Experiment Against Power: Towards Our Decolonial and Archipelagic Futures

${ }^{2}$ Doctora en Literatura, Duke University. Profesora adjunta, Programa de Literatura Comparada, Departamento de Humanidades, Universidad de Puerto Rico, Recinto Universitario de Mayagüez.Correo electrónico: b.llenin.figueroa@gmail.com
} 
with a glance at the current intensification of neoliberal capitalism and US-imperialism. Finally, two forms of emancipatory experimentation towards our dreamed future are reviewed: (1) the intensification of communitarian sovereignties, and (2) some of the possible connections between Puerto Rico, the West Indies Federation and CARICOM.

Keywords: Puerto Rico, island-laboratory, archipelagos, decolonization, communitarian sovereignties

Este artículo ofrece una mirada sobre algunos elementos de la investigación archipelágica más amplia de la que forma parte, preliminarmente titulada Archipiélago entre lo atroz y lo luminoso: hacia los futuros decoloniales de Puerto Rico. La misma se concibe como una aportación a lo que idea destroying muros ${ }^{3}$ llama "archipiélagos postexóticos": “". [...] la forma geográfica de nuestras relaciones, una representación de las vidas anticapitalistas en las que estamos comprometidas" (2018: 13). Por un lado, la investigación persigue trazar historias e imaginarios de conexión archipelágica entre Puerto Rico y el resto del Caribe, refutando así la ideología insularista de la carencia y el aislamiento como atributos "naturales" de la geografía. Por otro lado, figura las islas de Puerto Rico desde quienes las vivimos, las amamos y las imaginamos otras como archipiélago-experimento de emancipación contra el poder.

Aunque este trabajo identifica y denuncia la explotación de las islas como laboratorios de experimentación a conveniencia del poder capitalista colonial patriarcal, es preciso señalar que la experimentación como práctica artística o científica de la imaginación, la especulación y la creación es un significante abierto y, a mi modo de ver, imprescindible, para cualquier proyecto político emancipatorio. Así, este ensayo se interesará por conceptualizar a Puerto Rico como "archipiélago-experimento" contra el poder, en oposición a su significación como "isla-laboratorio" a beneficio del poder. Se trata de lo que, en otro registro, la escritora puertorriqueña Marta Aponte Alsina llamó "la isla experimental", en la que "[...] la rata de laboratorio que se siente observada, clasificada y anotada devuelve la mirada" (Aponte Alsina, 2013, resaltado añadido). Ante el escenario contemporáneo, caracterizado por la explotación de Puerto Rico como "laboratorio de austeridad", solo en conexión archipelágica con el resto del Caribe y por medio de prácticas experimentales de democracia participativa, podremos generar las propuestas imaginativas -prerrequisitos de la acción política- que nos urgen, en pos de futuros decoloniales y archipelágicos para Puerto Rico. ${ }^{4}$

\footnotetext{
${ }^{3}$ Según se indica en su página web, ideadestroyingmuros es "....un colectivo transcultural situado en la creación artística comunitaria. nace en venecia en 2005 y su nombre hace referencia al título de la composición musical de luigi nono "voci destroying muros" (sic) (1970)".

${ }^{4} \mathrm{Mi}$ actual proyecto de investigación se nutre de múltiples sintonías con el trabajo investigativo más reciente de Yolanda Martínez-San Miguel. Por una parte y, en sentido general, compartimos la articulación y defensa de una conceptualización amplia y elástica de "archipiélago" y "archipielagismo" (ver, por ejemplo, Martínez-San Miguel, 2018 y 2018a), incluso como un paradigma metodológico y, en mi caso, abiertamente político, para "imaginar la futuridad del Caribe" (Martínez-San Miguel, 2018: 59). Por otra parte, y de manera particular, mi trabajo -aunque ello no forma parte del presente ensayo- aborda una de las exhortaciones que Martínez-San Miguel hiciera a los efectos de que se estudie comparativamente la Confederación Antillana y la West Indies Federation (2018: 50). Asimismo, concibo textos literarios caribeños -así como otras manifestaciones artísticas y culturales- en conexión con el pensamiento archipielagista y confederacionista, ejercicio que Martínez-San Miguel también ha ejemplificado (2019).
} 


\section{La isla-laboratorio del poder: repaso histórico}

En la primera parte del estudio Imagined Islands: A Caribbean Tidalectics, he demostrado el amplio espectro de usos y abusos de las islas globales en el imaginario y la historia capitalista-colonial-patriarcal de Occidente, cifrado, en última instancia, en la negación y la carencia (Llenín Figueroa, 2012). Al interior del imaginario y la historia dominantes, las islas -entendidas como antónimo de los continentes, a pesar de que todas las tierras del planeta están completamente rodeadas por agua- han sido "desconocidas y luego descubiertas, desiertas, salvajes e infernales, incontaminadas, paradisíacas y exóticas” (ideadestroyingmuros, 2018: 13). Mas, para quienes las viven, las aman y las imaginan otras, "[...] las islas corresponden a lugares que han sufrido y siguen sufriendo formas de dominación nacional, económica y turística. [...] se vuelven pesadas: lugares para perder a los cuales es difícil volver, lugares de descolonizar, siempre presentes en nuestras auto representaciones e interpretaciones de lo real" (13).

Sabemos bien que, concebidas como laboratorios de y para el poder, las islas no se "vuelven pesadas" por la acción de "la naturaleza" y sus procesos, sino como resultado de verse sometidas a toda suerte de experimentación para solucionar las variadas crisis del régimen dominante. Estas crisis pueden resumirse como propias de los siguientes órdenes:

1. disciplinarias-ideológicas: en referencia al uso protagónico de las islas en las artes, incluso en el sentido mismo de la poesis; en la antropología, la arqueología, la geografía y la cartografía, entre otras disciplinas;

2. mítico-existenciales: relativas a la exploración del "yo" en una "isla desierta;" las islas-monstruos que producen, por negación, el sujeto respetable, racional y masculino preferido por Occidente; la máquina turística de la felicidad;

3. jurídicas o del derecho: cuando las islas son utilizadas como "estados de excepción," prisiones, espacios de destierro y máquinas de tortura para todo tipo de "indeseables" sociales;

4. políticas: acerca de las guerras por y en las islas y sus usos para territorializar los océanos;

5. climatológicas: apelan a las islas como marginalia que padece los peores estragos del cambio climático producido por los imperios; las islas como objetos de estudio de ecosistemas que desaparecen como resultado de la acción humana. ${ }^{5}$

Simultáneamente con los usos y abusos esbozados, la insularidad caribeña, en particular, se ha pensado y diseñado como laboratorio para la consolidación y expansión de todas las fases del capital colonial patriarcal. Para empezar, el proyecto capitalista colonizador europeo, en sí mismo, se figuró simbólicamente en función de la insularidad, como Balasopoulos explica al notar la profunda transformación de la perspectiva europea sobre la insularidad, pues del modelo anti- expansionista que en las eras clásica y medieval sostenía la visión sobre la isla, se pasó, a partir del siglo XVI, a la percepción de la isla-como-propiedad:

\footnotetext{
${ }^{5}$ Para una lista de referencias sobre los referidos usos y abusos de la insularidad véase bibliografía respectiva en Llenín Figueroa, 2012.
} 
It is important in this respect to reflect on the shift from the fundamentally anti-expansionist insularism of classical and medieval Europe to the post sixteenth-century elevation of 'the motif of the island' into what [Diana] Loxley describes as 'the theme of colonialism.' If, as Christian Jacob has argued, islands formally highlight the link between represented space and the inscription of the toponym, they inevitably also foreground the toponym's association with claims 'of precedence and of symbolic ownership, analogous to the political and colonial mastery suggested by the name of the sovereign.' In Rod Edmond and Vanessa Smith's related argument, colonial desire is quite literally the engine that mobilizes the cartographical vision of islands in the era of maritime colonialism: to the extent that islands 'look like property' (that is to say, to the extent that their small size appears to invite their capture by a synoptic gaze), they are likely to appear not merely as ideal states but also as 'ideal colonies', bite-size parcels of territory that stir fantasies of symbolic possession (Balasopoulos, 2008: 11).

En términos materiales, como demuestra Sidney Mintz en Sweetness and Power, el Caribe insular fue explotado como laboratorio para perfeccionar y expandir el capitalismo mercantil asociado con los clásicos modelos imperiales de Europa occidental y, a la vez, para impulsar el desarrollo del capitalismo industrial, con el sistema de la plantación como eje primordial de dicho proceso. Mintz describe las plantaciones como "precocious cases of industrialization" (1986: 59). ${ }^{6}$ La plantación, como sistema, adquirió y, de hecho, fomentó, muchas de las características del capitalismo industrial posterior: la regulación de los cuerpos y del tiempo de trabajo, la organización de una concentración espacial masiva de la mano de obra, el notable uso de maquinaria, la separación del ámbito de la producción del ámbito del consumo, la separación de las y los trabajadores de las herramientas de su trabajo (50-52). A su vez, la plantación retuvo características del capitalismo mercantil, especialmente, el uso de mano de obra esclavizada o por contratos no remunerados (indentured labor) y el hecho de ser una empresa fundamentalmente agrícola, aun si altamente mecanizada (56-59). ${ }^{7}$

Del sistema de la plantación, bisagra entre el capitalismo mercantil y el industrial, la explotación del Caribe insular se extendió a su uso como laboratorio para la transición del capitalismo industrial al postindustrial (financiero o neoliberal) actual, marcado por el turismo masificado, las economías dependientes y de servicio, la "flexibilización" de la clase trabajadora y los "paraísos fiscales", como bien demuestra Aarón Gamaliel Ramos en su libro Islas migajas: los países no independientes del Caribe contemporáneo (2016). Para lograr la explotación y sujeción del Caribe a la maquinaria capitalista colonial patriarcal, ha sido determinante la creciente y sistemática fragmentación de las conexiones interinsulares y archipelágicas que caracterizaron la zona caribeña

\footnotetext{
${ }^{6}$ En su libro Capitalism and Slavery, Eric Williams (1994) demuestra también que la esclavitud en el Caribe y las Américas financió la llamada Revolución Industrial y el desarrollo de la banca comercial.

${ }^{7}$ Mintz insiste, además, en el carácter industrial de la plantación de cara al consumo. A pesar de que el azúcar se consumía en Europa desde mucho tiempo antes, la introducción de azúcar del Caribe en la metrópolis "[...] nourished certain capitalist classes at home as they were becoming more capitalistic" (1986: 61). Al mismo tiempo, dicho producto se convirtió en un fenómeno de masas en Europa, precisamente, como resultado de su consumo por el proletariado industrial, en contraste con su previo consumo mayoritariamente por las elites. Mintz nos recuerda que el azúcar se volvió una fuente calórica crucial para las y los trabajadores, en vista del explotador régimen de trabajo industrial al que eran sometidos (146). Así, pasó a formar parte de un sistema de "legitimized population control", cuyo blanco primordial -propio del patriarcado- fueron las mujeres y las niñas, "...with the costly protein foods being largely monopolized by the adult male, and the sucrose being eaten in larger proportion by the wife and children" (149).
} 
antes de la irrupción de los imperios europeos.

Por una parte, la multiplicidad y competencia inter-imperial en el Caribe -a lo largo de varios siglos- impuso distintos modos de subyugación y explotación, incluyendo las diversidades lingüísticas y aquellas legales respecto al "contacto" de género y racial, generando así una variada gama de discontinuidades, rupturas y fragmentaciones en el archipiélago. A su vez, el legado de dicho proceso de fragmentación incluye, entre otras, la infiltración del racismo sistemático que justificó ideológicamente la sanguinaria esclavización liderada por Europa occidental, el creciente desmantelamiento de los transportes interinsulares marítimos, el debilitamiento de las relaciones económicas entre los países caribeños -al ser puestos en competencia como resultado de acuerdos económicos neoliberales decididos y gestados en beneficio de América del Norte- y las restricciones propias de modelos de neocolonialismo para la colaboración regional en el Caribe.

\section{La isla-laboratorio del poder: Puerto Rico como caso paradigmático}

El caso de Puerto Rico es paradigmático de la explotación de la insularidad para el desarrollo, transformación y expansión del capital colonial patriarcal. Tras la invasión del archipiélago en 1898 y la imposición de un gobierno militar por parte de EE.UU., el debate jurídico asociado con los “casos insulares" durante los primeros años del siglo XX marcó la pauta conceptual y política de Puerto Rico como isla-laboratorio. ${ }^{8}$ Como bien demuestran Efrén Rivera Ramos (1998) y José Atiles-Osoria (2016), el resultado de dicha experimentación legal-colonial -"Puerto Rico es propiedad de, pero no parte de los EEUU"- constituyó una nueva formulación histórica para evadir el estatus imperial colonial de la "relación" EE.UU.-Puerto Rico, de cara a la esfera internacional $\mathrm{y}$, a la vez, para producir una zona altamente juridificada en la que se insertaría por fuerza toda posterior resistencia política al colonialismo estadounidense en Puerto Rico. Así, y de la mano de la militarización del archipiélago con la construcción de múltiples bases militares durante las primeras décadas del siglo XX, se ha facilitado desde entonces la aceleración de la explotación de Puerto Rico como laboratorio de y para el poder. ${ }^{9}$ Durante las primeras décadas de la colonización estadounidense, Puerto Rico pasó del mercantilismo en la cúspide de la industrialización (centrales azucareros) del imperio español, al monopolio industrializado de empresas azucareras ausentistas, "hermanas", a su vez, de otras compañías estadounidenses en Latinoamérica tales como la United Fruit Company.

Al mismo tiempo, y durante la transición hacia la experimentación colonial-legal que es el propio "Estado Libre Asociado" (ELA), EE.UU. impulsó experimentos eugenésicos de control poblacional, "pureza racial" y explotación de los cuerpos de las mujeres en Puerto Rico. Según consigna

\footnotetext{
${ }^{8}$ Los "casos insulares" es el nombre colectivo para referirse a varios casos dilucidados por el Tribunal Supremo de los Estados Unidos de América entre 1901 y 1922, en la inmediatez de la expansión imperialista transoceánica de EE.UU. tras la Guerra de 1898. En su conjunto, las decisiones judiciales en estos casos crearon la doctrina legal del "territorio no incorporado" ("propiedad de, pero no parte de") para concebir a Puerto Rico, Guam y Filipinas a partir de un marco ideológico con claras evidencias racistas y discriminatorias. Además del influyente ensayo de Efrén Rivera Ramos y del reciente libro de José Atiles-Osoria citados en el cuerpo del texto, véase la excelente colección de ensayos editada por Christina Duffy Burnett y Burke Marshall, 2001.

${ }^{9}$ Para tener un panorama acerca de las instalaciones militares estadounidenses en Puerto Rico véase García Muñiz, 1991.
} 
Ana María García en el documental La operación (1982), a mediados de la década del cuarenta, y por espacio de más de dos décadas, en Puerto Rico se llevó a cabo una campaña de esterilización forzada. Como de costumbre bajo el capitalismo colonial patriarcal (Federici, 2004), la violencia institucional se encarnizó mayoritariamente contra las mujeres más vulnerables de la colonia, usándolas como objeto de laboratorio para que la industria farmacéutica experimentara con procesos de esterilización y, de paso, “mejorara la raza”. En su análisis de este proceso, Rachell Sánchez-Rivera rastrea la representación y discusión de las medidas de control poblacional en tres de los emergentes periódicos del país desde mediados de los cuarenta hasta mediados de los setenta. Con claridad brutal, la siguiente cita de un artículo de 1946, publicado en El Mundo - y recogido por Sánchez-Rivera — revela la indecible violencia contra las mujeres: "Dentro del problema poblacional, a Puerto Rico se le llama “el laboratorio poblacional del mundo"” (2017: 102).

A partir de los cincuenta, con la anuencia del ascendente Partido Popular Democrático, su líder Luis Muñoz Marín y su plataforma neocolonial del ELA, el imperio forzó una industrialización experimental "por invitación" en el archipiélago, que se extendió por buena parte del siglo XX, con toda suerte de empresas de nula deseabilidad, tóxica ejecución y aún más escaso éxito. El ejemplo más contundente son las petroquímicas, cuyos restos enmohecidos de material altamente tóxico continúan en la actualidad contaminando varias zonas costeras. El éxito económico de algunas fábricas, en particular, las farmacéuticas -establecidas en el país como resultado de la "invitación" de exenciones contributivas- ha sido primordialmente para sus dueños, pues las y los puertorriqueños han devengado salarios, mas no se ha producido el fortalecimiento de una economía local de producción. Una vez abandonados los experimentos previos - aunque no sus nefastos efectos_- el país pasó en los años noventa a la era postindustrial del fin de "las 936". ${ }^{10}$ Con ello, se aceleró la huida de buena parte de las fábricas “exitosas”, así como las privatizaciones rampantes de bienes públicos, el endeudamiento a mansalva y los incentivos económicos a las más poderosas clases sociales locales e imperiales. ${ }^{11}$

A lo largo del siglo XX y lo que va del XXI, el derecho ha fungido como mecanismo neocolonial por excelencia para hacer posible semejantes dimensiones de expolio. Además de los ya señalados “casos insulares" y la constitución del ELA en 1952, es preciso tomar en cuenta el uso e implantación del "estado de excepción colonial" (Atiles-Osoria, 2016) para desalentar, desarticular y activamente reprimir la oposición anticolonial, así como las leyes contributivas que se impulsaron desde el momento mismo de la invasión a fines del siglo XIX (Dick, 2015). Estas leyes han sido protagónicas en

\footnotetext{
${ }^{10}$ Diane Lourdes Dick explica "las 936": "Pursuant to the Tax Reform Act of 1976, Congress revised the U.S. Tax Code, purportedly to provide for a more efficient system of exempting possessions corporations from income taxation. In place of the exemption mechanism previously codified, Congress enacted a new provision (codified as section 936) enabling U.S. corporations to elect to receive a tax credit equal to the portion of U.S. tax liabilities attributable to taxable income from sources outside the United States that relate to the active conduct of a trade or business within a U.S. possession and from qualified possession-source investment income" (2015: 70). Entre otros de esos incentivos se destacan también las leyes 20 y 22 de 2012.

${ }^{11}$ Como documentación acerca de los procesos históricos en Puerto Rico durante el siglo XX y las primeras décadas del XXI que aquí he resumido, véanse, además del libro de Ramos ya señalado: Díaz Quiñones, 2000; Álvarez Curbelo, 2001; Gaztambide-Géigel, 2006; Picó, 2008; Bernabé y Ayala, 2009 y Gibson, 2014. El reciente libro de Aponte Alsina, PR 3 Aguirre (2018), acerca de la zona suroeste de Puerto Rico en la que se han enclavado buena parte de los "experimentos" señalados, da cuenta de estos procesos combinando magistralmente la investigación de archivo, el diario de viaje y la creación literaria.
} 
los esfuerzos del poder capitalista colonial patriarcal de los EE. UU. para explotar en su beneficio la isla-laboratorio en que ha convertido a Puerto Rico.

La expresión más crasa de la subyugación de Puerto Rico hoy es, sin duda, la ley PROMESA, habilitado por la Fiscal Oversight and Management Board (FOMB) o Junta de Control Fiscal. ${ }^{12}$ Esta Junta, convertida en gobierno de facto, cuenta con la complicidad y obediencia de la mayoría de los miembros de las ramas ejecutiva, legislativa y judicial en Puerto Rico, dominadas por el Partido Nuevo Progresista (PNP), baluarte de la anexión de Puerto Rico a Estados Unidos. La Junta determina las rutas para la "recuperación" del país, a la vez que continúa ahondando sus crisis. Esta contradicción queda ampliamente evidenciada al examinar las decisiones tomadas y las medidas impuestas por la Junta desde que fuera constituida en el 2016 por Barack Obama, el por entonces presidente de EE. UU. ${ }^{13}$

A pesar de que los huracanes Irma y María dejaron un saldo de inefable devastación y muertes tras su paso por el archipiélago en septiembre de 2017, ni la Junta ni el gobierno local se han desviado del plan neoliberal antes descrito. Antes bien, para reconfigurar la economía puertorriqueña de modo que se beneficien aún más los intereses de entidades privadas y extranjeras, la Junta, el gobierno local y sus asesores han capitalizado el sufrimiento y el trauma de las y los puertorriqueños de a pie -muchos y muchas de las cuales han tenido que salir del país o siguen viviendo bajo toldos azules y sin acceso garantizado a servicios básicos- para implantar su plan más agresivamente. Si algo se ha puesto de manifiesto en meses recientes, ha sido la mayor intensificación de la crisis en Puerto Rico como resultado de las políticas descritas y de la capitalización del desastre. ${ }^{14}$ De este modo, el período que va de 2016 al presente ha convertido a Puerto Rico en un atroz "laboratorio de austeridad", como consigna el Centro de Periodismo Investigativo (CPI) y New York Magazine en su trabajo colaborativo "El gobierno como empresa: avanza un nuevo modelo de gestión pública en Puerto Rico", publicado en abril de 2019. La investigación denuncia el contrato de la firma McKinsey como principal consultor de la Junta de Control Fiscal, pagado con fondos públicos de un país quebrado: "Por sus servicios, McKinsey ingresa cada mes alrededor de \$3 millones. Hasta el pasado mes de enero [de 2019], la cuenta iba por $\$ 72$ millones en fondos públicos desde

\footnotetext{
12 Para un exhaustivo análisis de la ley PROMESA, véase Trigo, 2017.

${ }^{13}$ Por ejemplo, la Junta ha: (1) liderado el masivo asalto a la Universidad de Puerto Rico, que actualmente experimenta la reducción de un tercio de su presupuesto operacional, el desmantelamiento de su Sistema de Retiro y las alzas desproporcionadas en los costos de educación para estudiantes; (2) tomado medidas para proteger y expandir las exenciones contributivas y los "incentivos" a corporaciones y firmas privadas; (3) promovido una "reforma" laboral que devuelve el país a condiciones laborales similares a las del siglo XIX; (4) tomado decisiones para debilitar las cooperativas de ahorro y crédito locales en beneficio de la banca comercial; (5) apoyado el desmantelamiento del sistema público de educación primaria y secundaria por medio de la privatización y, en particular, el sistema de escuelas chárter; (6) estimulado la "flexibilización" de la legislación ambiental; (7) impulsado esfuerzos en pos de privatizar las pocas corporaciones públicas que quedan en Puerto Rico, tales como la Autoridad de Energía Eléctrica y (8) diseñado acuerdos con bonistas que someten a las y los puertorriqueños a mayores niveles de endeudamiento, por ejemplo, el recientemente aprobado acuerdo de COFINA.

${ }^{14}$ De la muy abundante y sólida documentación existente acerca de estos asuntos, destaco las siguientes referencias: Stiglitz y Guzmán, 2017; Cotto Quijano, 2018; Caraballo Cueto, 2018; Godreau-Aubert, 2018; Klein, 2018; Santory Jorge, 2018; Bonilla, 2018 y 2018a; Brusi, Godreau y Bonilla, 2018; y el número especial “Crisis” de la revista Voces del Caribe, de próxima publicación, editado por José Atiles, Jeffrey Herlihy y Beatriz Llenín Figueroa.
} 
noviembre del 2016, fecha en que la firma comenzó sus labores” (Valentín Ortiz y Rice, 2019). ${ }^{15}$

Todo lo anterior nos lleva a considerar que, la era contemporánea en Puerto Rico, sobre todo después de los huracanes de 2017, ha reactivado el uso generalizado de la ideología insularista. Esta dicta, como vimos, que las carencias y limitaciones que se experimentan en las islas son el resultado "natural" de la geografía y que, por lo tanto, "el desastre es de esperarse". En estas circunstancias, si algo es preciso que recordemos es que, más allá de la cuestión de la proporción, la insularidad como formación geográfica no es inherentemente vulnerable al desastre. Al referirme a la proporción, apunto al hecho de que, por ejemplo, huracanes de la magnitud de Irma y María tendrán impacto sobre la mayor parte, o toda, una población en la medida en que la extensión territorial sea menor. Pero, al mismo tiempo, el cambio climático, del que las islas no son responsables, produce la ascendente frecuencia, dimensiones y rapidez de crecimiento de dichos fenómenos atmosféricos. Tanto el trabajo de John Campbell (2009) como el de James Lewis (2009), que considera archipiélagos del Pacífico y del Caribe, demuestran que la vulnerabilidad de las islas ante eventos como ciclones, huracanes, terremotos o erupciones volcánicas es producida por lo que J. Lewis llama "disaster imperialism" (2009: 4), "by which response to disaster [is] used to promote imperial power and beneficence" (2009: 4).

El resultado es la erosión sistemática de las formas de resiliencia que las poblaciones nativas habían desarrollado por milenios. Al examinar los casos de Antigua, Tonga y las Islas Cook, Lewis concluye que, tras haber sido comunidades autosuficientes para las que los "natural hazards had been a fact of life" (2009: 4), el "disaster relief", corolario del imperialismo del desastre, ha tenido en dichas comunidades insulares un "negative impact [...] upon self-reliance, a counter to vulnerability". En otro registro, Hilary Beckles denuncia también la ideología del desastre a días del paso de los huracanes Irma y María por el Caribe:

Hurricane Irma's fury preceded Maria's by a deadly Caribbean second. Together they constitute the familiar sound of death and destruction reminiscent of a colonial past that clings to the present and is determined to possess and own the Caribbean future. The chain linked imperial legacy that still imprisons the islands, keeping them politically fragmented and economically divided, was exposed as both cause and effect of a fragile region still feeling the presence of an imperial ethos that assigns to them a reality of structural dependency. Irma-Maria blew away the roof of the long and ongoing imperial cover up, and critically, was revelatory of the horrific history that dwells in the ruins of the present (2017: s.p., resaltado añadido). ${ }^{16}$

\footnotetext{
${ }^{15}$ El CPI también ha asumido la responsabilidad -por virtud de la incompetencia y obstrucción de los gobiernos local y federal- de fiscalizar y contabilizar, de la manera más fidedigna hasta el momento, las personas que murieron por causas directa e indirectamente relacionadas con el huracán María. Véase, Centro de Periodismo Investigativo (CPI), Quartz y Associated Press, 2018. Los números más recientes indican que Puerto Rico perdió un 4\% de su población tras los huracanes de 2017: "the greatest population drop in the recorded history of the island, according to one demographer" (Associated Press, 2019).

${ }^{16}$ Más recientemente, Naomi Klein ha documentado el desmedido lucro capitalista a partir del "desastre" en su The Shock Doctrine: The Rise of Disaster Capitalism. Tras su visita a Puerto Rico en enero de 2018, la misma investigadora publicó The Battle for Paradise: Puerto Rico Takes on the Disaster Capitalists, un breve recuento de la versión más honda del "capitalismo del desastre" en el Puerto Rico colonial pos-María. Un breve documental, con el mismo título de este último libro, fue producido tras la investigación de Klein. Véase Klein, 2018a. Asimismo, para conocer los mortíferos efectos ecológicos del imperialismo del desastre estadounidense en el trópico, véase Tucker, 2007.
} 
Por otra parte, es preciso recordar que, aun cuando en la isla-laboratorio de Puerto Rico -así como en el resto de la región caribeña- se han sentido más dramáticamente los desgarros que la experimentación capitalista colonial patriarcal requiere para reproducirse, el Caribe no ha recibido un centavo en legítimas reparaciones por parte de los poderes imperiales, asunto que abordaré en la última sección de este ensayo. "La vitrina de la democracia", frase con la que Luis Muñoz Marín alardeó acerca del supuesto "progreso" de Puerto Rico pos-Constitución del ELA, fue, entonces, una cortina de humo y es, hoy, una "vitrina del desastre". Mientras se desangra la descendencia de "las y los condenados de la tierra" al interior de las islas, sintiéndolas como tumbas de las que urge escapar, la descendencia de los colonos patriarcas, que viaja en limosinas, helicópteros o yates, rehace la insularidad como su paraíso, no tan solo de playas, sol y "mujeres", sino de escondite para su descomunal botín de guerra: un capital móvil que evade todo impuesto, incluso toda identificación, y que puede comprar tanto, que hasta negocia la catástrofe. ${ }^{17}$

Es así como queda develada la falsedad de la premisa de que las islas son espacios de negación, aislamiento y carencia "por naturaleza" geográfica. En todo caso, "el desastre" de nuestras carencias contemporáneas es el resultado "natural" del capitalismo colonial patriarcal. La explotación de las islas como laboratorios de experimentación de las políticas de control, saqueo y exterminio que aseguran el desarrollo y expansión del régimen dominante, con sus auges y quiebras en pos del lucro a toda costa, solo puede resultar en muerte y toda suerte de privaciones para los y las isleñas. ${ }^{18}$ Mientras, quienes producen y se lucran de los "paraísos fiscales" fabricados en espacios insulares, de sus "criptoutopías" y de la emisión de bonos a sabiendas del monumental riesgo, claman cínicamente que "la crisis es una oportunidad". ${ }^{19}$

\section{Hacia Puerto Rico como archipiélago-experimento de emancipación}

Ante un escenario tan atroz como el anteriormente expuesto, y pretendiendo transformarlo, ¿qué y cómo hacer? En lo que sigue, comento brevemente dos casos concretos de democracia participativa, por un lado, y de conexión archipelágica, por el otro. En primer lugar, considero las soberanías comunitarias en Puerto Rico, fenómeno a un tiempo económico, social, político y cultural que está construyendo, de manera autónoma, solidaria y muchas veces anónima, la democracia participativa que tanta falta hace en el país para gestionar todas las formas de soberanía que requerimos. En segundo lugar, examino varios aspectos del esfuerzo histórico de la West Indies Federation y del aún vigente CARICOM, como parte del ejercicio archipelágico de insertar la necesidad de la descolonización de Puerto Rico en su contexto caribeño más amplio, refutando así las estructuras coloniales y neocoloniales de aislamiento y fragmentación entre nuestros archipiélagos. Puerto

\footnotetext{
${ }^{17}$ Lo que se sabe de quienes se benefician de la deuda de Puerto Rico, en medio de una atmósfera de extremo secretismo, lo debemos al trabajo investigativo del Centro de Periodismo Investigativo, la revista In These Times y la organización Hedge Clippers. Véase, respectivamente, Cintrón Arbasetti, 2017 y "Vultures in Puerto Rico", 2017. Sobre el lucro privado tras el paso de María por Puerto Rico, considérese la plétora de noticias, en medios locales y estadounidenses, sobre contratos corruptos -el más sonado fue el de la compañía Whitefish-, la privatización de la Autoridad de Energía Eléctrica y el desmantelamiento de la educación pública en pos de escuelas chárter -ambas medidas recientemente anunciadas por el gobernador, Ricardo Rosselló-, entre otras.

${ }^{18}$ La investigación Paradise Papers: Secrets of the Global Elite, que también se recoge -y actualiza- en la bitácora del International Consortium of Investigative Journalists, pone de manifiesto el protagonismo de la insularidad caribeña en el mega-negocio de la evasión contributiva y en el enriquecimiento astronómico de un porciento ínfimo de la población del planeta (Fitzgibbon y Starkman, 2017).

${ }^{19}$ Sobre los “criptoutópicos", véase Bowles, 2018 y Brusi, 2018.
} 
Rico debe imaginarse, hoy más que nunca, como un archipiélago-experimento de emancipación. Para ello, precisamos concebirlo al interior de y acompañado por la región caribeña y, al mismo tiempo, al interior de y acompañado por un proyecto democrático participativo.

\section{Soberanías comunitarias}

Contra las recrudecidas fuerzas del capital colonial patriarcal que examinamos en las primeras dos partes de este ensayo, el Puerto Rico de décadas recientes y, en particular, el de los pos-huracanes de 2017, está reimaginando, fortaleciendo e, incluso, creando formas de democracia participativa gracias a la labor y compromiso de las y los puertorriqueños que trabajan en sus comunidades con oído en tierra. Múltiples fenómenos confirman el fortalecimiento y la creación de espacios e imaginarios para pensar la descolonización al interior de prácticas de democracia participativa opuestas a las muecas de democracia ofrecidas por las organizaciones y partidos políticos tradicionales. Las soberanías comunitarias -algunas de las cuales se conocen en el ámbito local como formas de "autogestión," aunque no se reducen a ello- designan una inmensa variedad de prácticas económicas, sociales, políticas y culturales colectivas y comunitarias de auto-organización autónoma que materializan profundas y diversas soberanías en el Puerto Rico contemporáneo. Tales formas de soberanía -mucho más incluyentes que aquellas asociadas con el paradigma del Estado-Naciónconstituyen rutas hacia la descolonización de Puerto Rico fuera de los marcos institucionales establecidos, así como de sus plataformas y vicios tradicionales que de tantas maneras han llevado al país a la crisis actual y han traicionado a sus comunidades. Las soberanías comunitarias se amplifican a través de redes de solidaridad material y afectiva tejidas a diario al margen de los aparatos gubernamentales locales y federales, así como de las corporaciones multinacionales y firmas de inversionistas que han llegado a controlar la economía dependiente de la colonia puertorriqueña. Asimismo, las soberanías comunitarias conforman redes solidarias no sólo al interior del archipiélago puertorriqueño, sino también con y entre sus crecidas diásporas en los Estados Unidos. Finalmente, el ejercicio de las soberanías comunitarias fomenta cruciales -aunque muchas veces “invisibles"- procesos de agenciamiento y formación política dentro y fuera del archipiélago. ${ }^{20}$

No obstante, las soberanías comunitarias en Puerto Rico adolecen de la perspectiva archipelágica

\footnotetext{
${ }^{20}$ Entre las formas de soberanía comunitaria más recientes -aunque con una amplia trayectoria histórica de triunfos y legados en el país-, se encuentran las siguientes: 1.) Las numerosas luchas ecológicas, con amplios antecedentes en Puerto Rico. Entre estas se destacan el rescate comunitario de varias zonas de playa en la costa de Carolina que habrían sido "desarrolladas" por el Hotel Marriott; la lucha contra la incineradora de carbón AES en Tallaboa, Peñuelas y en otras áreas del sur como Guayama y Salinas, y la resistencia en Playuela, Aguadilla, contra la construcción de un "mega resort". Todas han desafiado el desarrollo irresponsable y la grave contaminación impulsadas por corporaciones privadas, al tiempo que se ha registrado en Puerto Rico un alza significativa en proyectos agroecológicos. 2.) El creciente apoyo ciudadano que está teniendo la energía solar y limpia, especialmente alrededor del trabajo de Casa Pueblo en Adjuntas e IDEBAJO en la costa sureste, así como su autonomía de corporaciones privadas o privatizadas. 3.) La fiscalización y oposición a la Junta de Control Fiscal por parte de múltiples organizaciones defensoras de la justicia social, tales como JunteGente, ¡Dignidad! y Colectiva Feminista en Construcción. 4.) El multitudinario apoyo a una auditoría transparente de la deuda, liderada por la ciudadanía, y cuyo proceso juzgaría a los responsables. Este esfuerzo ha sido impulsado principalmente por el Frente Ciudadano por la Auditoría de la Deuda y por Construyamos Otro Acuerdo. 5.) La campaña internacional que culminó con la liberación del prisionero político Óscar López Rivera en 2017. 6.) La continua lucha en defensa de la educación pública, accesible y de calidad, tanto a nivel escolar como universitario, por parte de organizaciones tales como la Federación de Maestros y Maestras de Puerto Rico, movimientos estudiantiles y colectivos universitarios docentes como PROTESTAmos y PAReS. 7.) La proliferación de brigadas y centros comunitarios, llamados Centros de Apoyo Mutuo, entre los que destacan el del Barrio Mariana en Humacao y varios en la zona metropolitana del país y 8.) El vibrante resurgimiento del arte, teatro y performance callejeros e independientes, con el trabajo de colectivos artísticos tales como Agua, Sol y Sereno; Papel Machete; Vueltabajo Colectivo y Bemba PR. Para más información sobre el ejercicio de las soberanías comunitarias actuales en Puerto Rico, véase Red de apoyo mutuo de Puerto Rico, 2018.
} 
respecto de la región caribeña que, a mi juicio, es indispensable para un proceso radical de descolonización y agenciamiento de soberanías. Con el propósito de resarcir dicha limitación, es preciso recuperar, examinar y enlazar todas las formas de conexión interinsular que se han producido en el Caribe, tanto en los frentes explícitamente políticos y sociales, como en aquellos que conforman lo que en una investigación más amplia denomino el "archivo afectivo" de Puerto Rico, compuesto por la literatura y las artes vivas. ${ }^{21}$ A continuación, consideraré una de tales formas de enlace interinsular en el ámbito político y económico. Se trata de las posibles conexiones entre Puerto Rico y algunos aspectos de la historia de la West Indies Federation y de los esfuerzos actuales de CARICOM en pos de lograr legítimas reparaciones para el Caribe por parte de los imperios europeos.

\section{West Indies Federation (WIF) y CARICOM}

La historia de la West Indies Federation (WIF) a mediados del siglo XX ha sido ampliamente analizada desde múltiples perspectivas y disciplinas. ${ }^{22}$ En el proyecto de libro del que este artículo forma parte disputo la prevalencia, al interior de la bibliografía sobre WIF, del determinismo geográfico y la ideología de la insularidad que utiliza dicha categoría como explicación "natural" de limitaciones que son, más bien, políticas. Sin embargo, en el contexto del interés de este ensayo por tender puentes entre la más amplia región caribeña y Puerto Rico, destaco dos semejanzas cruciales y una significativa diferencia entre los consensos aludidos y la situación actual en Puerto Rico. La primera semejanza es la incapacidad de producir movimientos populares en pos de la integración caribeña como necesidad fundamental para la descolonización. Dicha limitación, me parece, es un inmenso reto para los futuros decoloniales y archipelágicos de Puerto Rico que debemos reconocer y enfrentar abiertamente en el siglo XXI. Tales movimientos populares sólo podrían emerger si se estructuran según formas de democracia participativa que persigan soberanías multidimensionales: aquellas del cuerpo -género, raza, sexualidad, diversidad cognitiva y funcionaly aquellas de las fuentes y distribución de alimento, energía, salud, educación, cultura y transportación (Reyes Cruz, 2018).

\footnotetext{
${ }^{21}$ Por "archivo afectivo" me refiero a las diversas instancias en las que puede constatarse y documentarse el amor, la pasión, por el archipiélago (puertorriqueño, caribeño); en las que puede registrarse la convicción compartida de que, al decir de Brathwaite, "nuestra unidad es submarina"; y en las que se manifiesta que tal conciencia marítima y archipelágica necesita fortalecerse y materializarse en Puerto Rico si es que aspiramos a un futuro verdaderamente decolonial.

${ }^{22}$ Varios consensos emergen tras examinar la bibliografía existente: 1.) La idea de confederar las colonias británicas en el Caribe, en marcado contraste con la Confederación Antillana betancina del siglo XIX -como un ideal político revolucionario para fortalecer las posibilidades de Puerto Rico, la República Dominicana, Cuba y Haití de lograr, y mantener, la soberanía y una gobernanza republicana- surgió primero al interior de la administración imperial británica durante el siglo XIX, que alentó la idea como un mecanismo para reducir sus gastos administrativos, de modo que pudiese sustentar mejor el colonialismo británico en la región. Payne describe el fenómeno con acidez: "It was as if a succession of tidy minds, brooding over a map of the West Indies on some wall in Whitehall, could not resist devising plans for amalgamating these irritatingly dispersed islands into near and manageable groups" [2008: loc.190]). 2.) En las Antillas anglófonas y sus diásporas, la federación no se convirtió en una idea y horizonte político atractivos hasta las primeras décadas del siglo XX (Duke, 2016; Payne, 2008). El apoyo del gobierno británico en ese momento respondió a que sus colonias caribeñas no eran ya la fuente de riqueza que habían sido en el pasado, ni tenían para el imperio el mismo interés geopolítico. 3.) El apoyo local y diaspórico fue principalmente de intelectuales, académicas, artistas, activistas y figuras del gobierno, pero la federación nunca llegó a convertirse en un movimiento de base con apoyo masivo de la mayoría de las y los antillanos. 4.) El largo y enrevesado proceso de negociación que culminó en la declaración de WIF en 1958, y su relativamente rápida disolución en 1962, se caracterizó por significativas fricciones entre posiciones "insulares" y "regionales", entre partidos políticos opuestos entre sí a nivel local -especialmente en Jamaica- y entre líderes políticos masculinos de alto perfil -en particular, Eric Williams, Norman Manley y Alexander Bustamante-, cuyas limitaciones personales han sido interpretadas por algunos comentaristas como la razón principal del colapso de WIF, véase por ejemplo Padmore, 1999 y O’Neil, 1999.
} 
El segundo asunto en común entre la historia de WIF y Puerto Rico es el hecho que, aún desde el movimiento abolicionista del siglo XIX (Araujo, 2017), del que Betances (“el antillano") fue protagonista, en Puerto Rico se ha ignorado consistentemente la exigencia de reparaciones (reparatory justice) a los imperios español y estadounidense. En el contexto actual de profunda crisis humanitaria y fiscal, esta cuestión es de la más honda seriedad. El hecho de que Puerto Rico sea privado por los EE.UU. de ser miembro activo de CARICOM (López Vera, 2005) constituye otro obstáculo para que tal asunto esté, al menos, en el escenario público de debate político, pues, como veremos a continuación, CARICOM está actualmente liderando una campaña de reparaciones que ya ha sido públicamente apoyada por múltiples organizaciones afroamericanas y por Cuba.

Por su parte, la diferencia notable entre Puerto Rico y la historia de WIF en el Caribe anglófono ha sido la ausencia, a lo largo de los siglos XX y lo que va del XXI en Puerto Rico, de una conciencia archipelágica equivalente a la del Caribe anglófono. A pesar del colapso de WIF, no hay duda de que la pregunta sobre la integración caribeña ha formado parte consistente e infatigablemente de la agenda política, social y económica del Caribe anglófono, mientras que, tras el ideal decimonónico de la Confederación Antillana, el escenario político puertorriqueño se caracteriza por un altisonante silencio respecto a nuestra condición compartida como archipiélago caribeño. Sin embargo, vale aclarar que el archivo afectivo puertorriqueño está saturado de perspectivas caribeñistas. Aunque el estatus de Puerto Rico como colonia de EE.UU. es causa principal de dicha ceguera, a nivel del debate político, hacia nuestra constitución archipelágica, el hecho es que ni siquiera los partidos políticos y movimientos que, explícitamente, defienden la descolonización han prestado atención a la integración con nuestra región archipelágica como un requisito indispensable para lograr su objetivo.

Debo añadir, por otro lado, dos limitaciones del proyecto de WIF, tal como fue negociado en sus orígenes, que no han sido destacadas por la bibliografía existente. En primer lugar, WIF estuvo material y simbólicamente inhabilitada en la medida en que no se pactó bajo la exigencia de reparaciones por parte del imperio británico tras siglos de esclavización y colonialismo, limitación que sólo recientemente está siendo atendida por CARICOM. ${ }^{23} \mathrm{El}$ objetivo de integración en el Caribe anglófono, en una palabra, ha pretendido encontrar amigos donde había solo enemigos, comportándose como si las crueles consecuencias de la esclavización y el colonialismo -incluyendo las ecológicas y epidemiológicas-, así como los inefables costos de la "construcción nacional" posterior, deben ser absorbidos por las y los sobrevivientes en vez de por los victimarios. En segundo lugar, ni WIF ni CARICOM han sido diseñados y ejecutados en el marco de un proyecto político transformador y emancipatorio, por lo cual han sido presa -desde sus propios orígenes-de la lógica capitalista y neocolonial, comenzando con las nociones de desarrollo industrial "por invitación” a

\footnotetext{
${ }^{23}$ Como nos recuerda Beckles en la columna antes citada: "These ravished islands have done their best to clean up the colonial mess. They have spent beyond their means in the process of seeking to convert colonials into citizens. Left largely illiterate and riddled with ill health by colonialism they have built schools and hospitals that must be maintained. Social expenditure in the interest of building democracy exceeds financial income. This is the price they paid for participation in modernity. Now their public debt strangles their quest for economic growth. It is a debt that should be written off as an investment in democracy" (2017).
} 
mediados del siglo XX por medio de exenciones contributivas y otros "incentivos", hasta el régimen neoliberal del "libre mercado" en la era contemporánea. Como resultado de ello, a pesar de que la integración caribeña ha estado, loablemente, en la agenda del Caribe anglófono a lo largo de varias décadas, esta se ha visto sistemáticamente socavada por la complicidad de los organismos que aspiran a construirla con las mismas estructuras de explotación que constituyen el legado imperialista. Hoy, el sueño de la integración, en Puerto Rico y el resto del Caribe, debe confrontar y atender autocríticamente las dos limitaciones señaladas, si es que aspiramos a que la conciencia y práctica archipelágicas se conviertan en un ideal político compartido por las mayorías antillanas.

Por otra parte, CARICOM, fundado en 1973, como quizá el más conocido y duradero heredero de WIF, ha buscado fomentar y sustentar múltiples formas de "integración funcional" de los países caribeños, en ausencia de una total integración política. ${ }^{24}$ Para propósitos de este artículo, enfatizo específicamente un esfuerzo en curso de integración funcional por parte de CARICOM para contrarrestar una de las limitaciones fundacionales de WIF. Se trata del 10-Point Call de 2013 impulsado por CARICOM para exigir justicia reparatoria a los históricos imperios europeos. En su libro, Reparations for Slavery and the Slave Trade, Ana Lucía Araujo resume la iniciativa de CARICOM del siguiente modo:

In 2013, CARICOM [...] decided that each country member would create a commission for reparations. Weeks later, CARICOM created a Reparations Commission chaired by Sir Hilary Beckles. [...] On March 11, 2014, the caucus gathering all presidents of CARICOM member states adopted a plan consisting of ten demands of symbolic and financial reparations for slavery, the Atlantic slave trade, and the genocide of indigenous populations. Addressed to Denmark, France, Portugal, the Netherlands, the United Kingdom, and Sweden, CARICOM's ten-point reparations plan includes a formal apology. [...] [and] "the reduction of domestic debt and cancellation of international debt." Most other measures of the plan are demands of symbolic reparations [...] (2017: 175-176).

Es imperativo que Puerto Rico se adhiera a este esfuerzo pancaribeño de integración funcional. Para ello, urge que continuemos desahuciando el modelo tradicional de trabajo político -desde arriba e institucionalizado- que ha caracterizado las plataformas políticas decoloniales en Puerto Rico. La adhesión requerirá trabajo político creativo y desde las bases, pues, en el escenario actual, como vimos, Puerto Rico está impedido por los EE.UU. de ser miembro activo de CARICOM. Las reparaciones -tanto conceptual como políticamente- deben estar en el centro de la democracia participativa que estamos cultivando en Puerto Rico tras la devastación de 2017.

La evidencia histórica sugiere que lograr el estatus formal de "estado-nación independiente" no asegura, de ninguna manera, un futuro decolonial para las ex colonias. Más aún, a pesar de la idea generalizada que sugiere que alcanzar el estatus de estado-nación es un prerrequisito para

\footnotetext{
${ }^{24}$ Anthony Payne, en The Political History of CARICOM, se refiere a las políticas de CARICOM como esfuerzos de "regionalization" en lugar de "regionalism" (2008: loc. 6723-6739). Mientras, Jessica Byron y Patsy Lewis las describen como "intergovernmental cooperation" en vez de "supranational integration" (2018: loc. 1651).
} 
la integración caribeña, la evidencia indica que tal estatus se ha vuelto, más bien, un obstáculo práctico y político en el curso de la integración supranacional. Siguiendo el argumento de Bonilla (2015) concerniente al Caribe francófono no soberano, podemos interpretar que la experiencia "sísmica" de reorganización política que atraviesa el escenario puertorriqueño actual podría llevarnos a abandonar al estado-nación independiente como el único horizonte político emancipatorio. En esa perspectiva, nuestro futuro decolonial debe cifrarse en prácticas archipelágicas y de democracia participativa, esto es, en reclamar nuestras islas como archipiélago-experimento de emancipación contra el poder.

Las isleñas podemos encontrar algunas de esas prácticas en nuestra historia e imaginarios "postexóticos" del pasado y del presente. Es preciso que alimentemos las conexiones archipelágicas ya establecidas a pesar de los legados del imperialismo, a través de organizaciones de base comunitaria, trabajo activista, alianzas universitarias y nuestro archivo afectivo. Por ello, urge rescatarlas del olvido institucional -forzado o indirecto- y examinar sus aciertos y desaciertos. Es imperativo, al mismo tiempo, que continuemos alimentando nuestros experimentos emancipatorios con formas aún más hondas de democracia y conexión archipelágica, entre las que valdría la pena experimentar, por ejemplo, con la creación, divulgación y réplica de cooperativas archipelágicas caribeñas en materia de las múltiples formas de soberanía que, como vimos, estamos en curso de construir.

\section{EPÍLOGO}

Este ensayo terminó de escribirse en abril de 2019 y muy pronto, en julio, para sorpresa de muchxs activistas y académicas agotadas ante el desalentador panorama político del país, Puerto Rico dio cátedra internacional de un experimento emancipatorio, con claros visos de prácticas de democracia participativa, que resultó en la renuncia -efectiva el 2 de agosto- del entonces gobernador Ricardo Rosselló y en el reordenamiento de nuestro imaginario político colectivo. El movimiento del verano revolucionario puertorriqueño se caracterizó por la organización multiforme, multifocal, colectiva, horizontal y sin lideratos jerárquicos ni masculinistas. A lo largo y ancho de todo el archipiélago, el agenciamiento popular, propio de las soberanías comunitarias aquí discutidas, fue contundente, manifestándose de múltiples modos, entre los que destacan las artes transdisciplinarias -por ejemplo, performance, pintura de cuerpo, arte gráfico, muralismo, baile y diversas formas de textualidad, entre otras- y las prácticas culturales y políticas transgeneracionales -por ejemplo, los tradicionales paros y marchas, las manifestaciones a caballo, en motora o en kayak, la "yoga combativa", el "vogueo" cuir y el "perreo combativo". ${ }^{25}$ Estamos, sin duda, haciendo la historia de nuestro futuro decolonial y archipelágico, para la cual la intelectualidad, a mi modo de ver y como ya he planteado en otra parte (Vilches Norat, Llenín Figueroa et al., 2019), debe abandonar los modelos teleológicos, proféticos y pontificadores. En el Puerto Rico pos verano 2019, insistamos en que todo es posible y refrendemos el antiquísimo "yo solo sé que no sé nada".

${ }_{25}$ Entre la reciente documentación de este proceso, destaco las columnas de Bonilla (2019); Bonilla y Caraballo Cueto (2019); Lebrón (2019); Dávila y LeBrón (2019); y Bernabe y Rodríguez Banchs (2019). 


\section{BIBLIOGRAFÍA}

Álvarez Curbelo, S. (2001). Un país del porvenir: el afán de modernidad en Puerto Rico, siglo XX. San Juan: Ediciones Callejón.

Aponte Alsina, M. (2013). La metáfora madre. 80grados: prensa sin prisa, 8 marzo. Recuperado de https://www.80grados.net/la-metafora-madre/

Aponte Alsina, M. (2018). PR 3 Aguirre. Cayey: Sopa de Letras.

Araujo, A. L. (2017). Reparations for Slavery and the Slave Trade: A Transnational and Comparative History. London y Oxford: Bloomsbury.

Associated Press (2019). Puerto Rico Lost Nearly 4\% of Its Population after Hurricane María, Data Show. Los Angeles Times, 18 abr. Recuperado de https://www.latimes.com/nation/ la-na-puerto-rico-population-hurricane-maria-20190418-story.html

Atiles-Osoria, J. (2016). Apuntes para abandonar el derecho. Cabo Rojo: Editora Educación Emergente.

Balasopoulos, A. (2008). Nesologies: Island Form and Postcolonial Geopoetics. Postcolonial Studies, 11 (1), 9-26. Doi:10.1080/13688790801971555

Beckles, H. (2017). Irma-Maria: A Reparations Requiem for Caribbean Poverty. The University of the West Indies Open Campus, 22 septiembre. Recuperado de www.open.uwi.edu/ irma-maria-reparations-requiem-caribbean-poverty

Bernabe, R. y C. J. Ayala (2009). Puerto Rico in the American Century: A History since 1898. Chapel Hill: U of North Carolina P.

Bernabe, R. y Rodríguez Banchs, M. (2019). Verano 2019: balances y perspectivas. 80grados: prensa sin prisa, 2 agosto. Recuperado de https://www.80grados.net/verano-2019-balances-y-perspectivas/

Bonilla, Y. (2015). Non-Sovereign Futures: French Caribbean Politics in the Wake of Disenchantment. Kindle ed. Chicago: U of Chicago P.

Bonilla, Y (2018). Trump's False Claims about Puerto Rico Are Insulting. But They Reveal a Deeper Truth. The Washington Post, 14 sep. Recuperado de https://www.washingtonpost. com/outlook/2018/09/14/trumps-false-claims-about-puerto-rico-are-insulting-they-revealdeeper-truth/?noredirect $=$ on\&utm_term $=.889 \mathrm{fcc} 7 \mathrm{ab} 85 \mathrm{~b}$ 
Bonilla, Y (2019). “Meet the Women Who Toppled Puerto Rico’s Governor”. MTV News, 2 agosto. Recuperado de http:/www.mtv.com/news/3133648/women-puerto-rico-governor-rossello/

Bonilla, Y y Caraballo Cueto, J. (2019). "Puerto Rico: Increased Federal Control Is Not the Solution”. The Hill, 27 julio. Recuperado de https://thehill.com/opinion/campaign/455018puerto-rico-increased-federal-control-is-not-the-solution

Bonilla, Y [et al.] (2018a). Puerto Rico Syllabus. Recuperado de https://puertoricosyllabus.com

Bowles, N. (2018). Making a Crypto Utopia in Puerto Rico. The New York Times, 2 feb. Recuperado de www.nytimes.com/2018/02/02/technology/cryptocurrency-puerto-rico.html

Brusi, R. (2018). Críptidos. 80grados: prensa sin prisa, 23 febrero. Recuperado de http://www.80grados.net/criptidos/

Brusi, R.; I. Godreau y Y. Bonilla (2018). When Disaster Comes for the University of Puerto Rico. The Nation, 20 septiembre. Recuperado de https://www.thenation.com/article/when-disaster-capitalism-comes-for-the-university-of-puerto-rico/

Burnett, C. D. y B. Marshall, (Eds.) (2001). Foreign in a Domestic Sense: Puerto Rico, American Expansion, and the Constitution. Durham: Duke UP.

Campbell, J. (2009). Islandness: Vulnerability and Resilience in Oceania. Shima: The International Journal of Research into Island Cultures, 3(1), 85-97. Recuperado de http://shimajournal.org/issues/v3n1/i.-Campbell-Shima-v3n1-85-97.pdf

Caraballo Cueto, J.(2018). ¿Qué causó la crisis de deuda?. El Nuevo Día, 12 julio. Recuperado de https:// www.elnuevodia.com/opinion/columnas/quecausolacrisisdedeuda-columna-2434509/

Centro de Periodismo Investigativo (CPI), Quartz y Associated Press (2018). Los muertos de María. Recuperado de https://losmuertosdemaria.com/

Cintrón Arbasetti, J.; C. Minet; A. V. Hernández; J. Stites (2017). Who Owns Puerto Rico’s Debt, Exactly? We've Tracked Down 10 of the Biggest Vulture Firms. In These Times, 17 octubre. Recuperado de http://inthesetimes.com/features/puerto_rico_debt_bond_holders_ vulture_funds_named.html

Cotto Quijano, E. (2018). How the Triple Tax Exemption on Puerto Rico's Bonds Financed Its Territorial Status -and Helped Spark Its Debt Crisis. Pro-Market: The Blog of the 
Stigler Center at the U of Chicago Booth School of Business, 11 septiembre. Recuperado de https://promarket.org/triple-tax-exemption-puerto-ricos-bonds-financed-territorial-status-helped-spark-debt-crisis/

Dávila, V. y LeBrón, M. (2019). How Music Took Down Puerto Rico’s Governor. The Washington Post. 1 agosto. Recuperado de https://www.washingtonpost.com/outlook/2019/08/01/ how-music-took-down-puerto-ricos-governor/?curator=MusicREDEF

Díaz Quiñones, A. (2000). El arte de bregar. San Juan: Ediciones Callejón.

Dick, D. L. (2015). U.S. Tax Imperialism. American University Law Review. 65(1), 1-86. Seattle University School of Law Digital Commons. Recuperado de https://digitalcommons.law. seattleu.edu/cgi/viewcontent.cgi?article $=1729 \&$ context $=$ faculty

Duke, E. D. (2016). Building a Nation: Caribbean Federation in the Black Diaspora. Gainesville: UP of Florida.

Edmond, R., and V. Smith, eds. (2003). Islands in History and Representation. London: Routledge.

Federici, S. (2004). Caliban and the Witch: Women, Body and Primitive Accumulation. Brooklyn: Autonomedia.

Fitzgibbon, W. y D. Starkman (2017). The "Paradise Papers" and the Long Twilight Struggle Against Offshore Secrecy. International Consortium of Investigative Journalists, 27 diciembre. Recuperado de https://www.icij.org/investigations/paradise-papers/paradise-papers-long-twilight-struggle-offshore-secrecy/

García, A. M. (Directora) (1982). La operación (video). YouTube. Recuperado de https://www. youtube.com/playlist?list=PLSFvl4lWGgT6dV7vVCuYz_bXALfVjGYEO

García Muñíz, H. (1991). U.S. Military Installations in Puerto Rico: An Essay on Their Role and Purpose. Caribbean Studies 24(3/4), 79-97.

Gaztambide-Géigel, A. (2006). Tan lejos de Dios: ensayos sobre las relaciones del Caribe con Estados Unidos. San Juan: Ediciones Callejón.

Gibson, C. (2014). Empire's Crossroads: A History of the Caribbean from Columbus to the Present Day. London: Pan Macmillan.

Godreau-Aubert, A. (2018). Las propias: apuntes para una pedagogía de las endeudadas. Cabo 
Rojo: Editora Educación Emergente.

idea destroying muros (2018). postexótico. relaciones, archipiélagos y comunidades otras. [s.1.]: Pensaré cartoneras. Recuperado de https://issuu.com/pensarecartoneras/docs/postexoticokgmk

idea destroying muros [2019]. "Who we are". ideadestroyingmuros. Recuperado de http://www. ideadestroyingmuros.info/bio/chi-siamo/

Klein, N. (2007). The Shock Doctrine: The Rise of Disaster Capitalism. New York: Picador.

Klein, N. (2018). The Battle for Paradise: Puerto Rico Takes on the Disaster Capitalists. Chicago: Haymarket Books.

Klein, N. (2018a). The Battle for Paradise: Naomi Klein Reports from Puerto Rico. The Intercept, 7 abril. YouTube. (video). Recuperado de https://www.youtube.com/watch?v=pTiZtYaB$3 Z$ o\&feature $=$ share

LeBrón, M. (2019). The Protests in Puerto Rico Are About Life and Death. NACLA. 18 jul. Recuperado de https://nacla.org/news/2019/07/18/protests-puerto-rico-are-about-life-and-death

Lewis, J. (2009). An Island Characteristic: Derivative Vulnerabilities to Indigenous and Exogenous Hazards. Shima: The International Journal of Research into Island Cultures, 3(1), 3-15. Recuperado de http://shimajournal.org/issues/v3n1/d.-Lewis-Shima-v3n1-3-15.pdf

Lewis, P. y J. Byron (2018). Responses to the Sovereignty/Vulnerability/Development Dilemmas. En P. Lewis; T.-A. Gilbert-Roberts y J. Byron (Eds.). Pan-Caribbean Integration Beyond CARICOM (loc. 1413-1925). Oxon y New York: Routledge.

Lewis, P.; T.-A. Gilbert-Roberts y J. Byron, eds. (2018). Pan-Caribbean Integration Beyond CARICOM. Kindle ed. Oxon y New York: Routledge.

Llenín-Figueroa, C. B. (2012). Imagined Islands: A Caribbean Tidalectics. (Tesis de doctorado). Duke University, Durham, NC. Recuperado de https://dukespace.lib.duke.edu/dspace/bitstream/handle/10161/5420/LlennFigueroa_duke_0066D_11264.pdf?sequence=1

López Vera, E. (2005). Las relaciones oficiales de Puerto Rico con el Caribe. Gloobalhoy, (1415:) s.p.

Martínez-San Miguel, Y. (2018). Colonialismo y decolonialidad archipelágica en el Caribe. Tabula 
Rasa, (29), 37-64.

Martínez-San Miguel, Y. (2018a). "El archipiélago pluriversal”. 80grados: prensa sin prisa. 6 abril. Recuperado de http://www.80grados.net/el-archipielago-pluriversal/

Martínez-San Miguel, Y. (2018b). West Indies/Caribe/Caribbean/Caraibes: fisuras del caribeñismo. 80grados: prensa sin prisa. 2 nov.iembre Recuperado de http://www.80grados.net/ west-indies-caribe-caribbean-caraibes-fisuras-del-caribenismo-notas-desde-miami/

Martínez-San Miguel, Y. (2019). Entre con/federaciones: Nicolás Guillén, Luis Palés Matos y Aimé Césaire. 80grados: prensa sin prisa. 28 junio. Recuperado de http://www.80grados. net/entre-con-federaciones/

Mintz, S. W. (1986). Sweetness and Power: The Place of Sugar in Modern History. New York: Penguin Books.

O’Neil Lewis, J. (1999). From West Indian Federation to Caribbean Economic Community. Social and Economic Studies 48(4), 3-19.

Padmore, G. (1999). Federation: The Demise of an Idea. Social and Economic Studies, 48(4), 21-63.

Payne, A. (2008). The Political History of CARICOM. 1980. Kingston y Miami: Ian Randle Publishers.

Picó, F. (2008). Historia general de Puerto Rico. San Juan: Ediciones Huracán.

Ramos, A. G. (2016). Islas migajas: los países no independientes del Caribe contemporáneo. San Juan: Travesier \& Leduc Editores.

Red de apoyo mutuo de Puerto Rico (2018). Recuperado de https://redapoyomutuo.org

Reyes Cruz, M. (2018). Por quiénes esperamos. 80grados: prensa sin prisa. 2 febrero. Recuperado de http://www.80grados.net/por-quienes-esperamos

Rivera Ramos, E. (1998). La construcción legal del colonialismo de los Estados Unidos: los casos insulares (1901-1922). El Otro Derecho, 22(8).

Sánchez-Rivera, R. (2017). "Imágenes y representaciones de la prensa puertorriqueña: control de natalidad, esterilización y anticonceptivos en El Mundo, El Imparcial y Claridad(1943-1974)." De raiz diversa: Revista Especializada en Estudios Latinoamericanos, 4(7), 101-135. Recuperado de https://www.researchgate.net/profile/John_Lopes3/publication/318825653 
Cultura_popular_e_propaganda_eleitoral_no_Rio_Grande_do_Norte_Brasil_uma_analise_na_perspectiva_discursiva_e_folkcomunicacional/links/5a142ab4aca27240e3086212/ Cultura-popular-e-propaganda-eleitoral-no-Rio-Grande-do-Norte-Brasil-uma-analise-na-perspectiva-discursiva-e-folkcomunicacional.pdf\#page $=99$

Santory Jorge, A. (2018). Nada es igual: bocetos del país que nos acontece. Cabo Rojo: Editora Educación Emergente.

Stiglitz, J. y M. Guzmán (2017). From Bad to Worse for Puerto Rico. Project Syndicate. 28 febrero. Recuperado de https://www.project-syndicate.org/commentary/puerto-rico-debt-plan-deep-depression-by-joseph-e--stiglitz-and-martin-guzman-2017-02\#comments

Trigo, M. de los Á. (2017). Los Estados Unidos y la PROMESA para Puerto Rico: un análisis de la ley para la supervisión, administración y estabilidad económica de Puerto Rico. San Juan: América en Libros.

Tucker, R. P. (2007). Insatiable Appetite: The United States and the Ecological Degradation of the Tropical World. Lanham: Rowman \& Littlefield Publishers.

Valentín Ortiz, L. J.; A. Rice (2019). El gobierno como empresa: avanza un nuevo modelo de gestión pública en Puerto Rico. Centro de Periodismo Investigativo. 17 abril. Recuperado de http:// periodismoinvestigativo.com/2019/04/el-gobierno-como-empresa-avanza-un-nuevo-modelo-de-gestion-publica-en-puerto-rico/

Vilches Norat, V.; Llenín Figueroa, B. et al. (2019). Un verano de combis completas. EAhora la turba. 1 agosto. Recuperado de https://ahoralaturba.net/2019/08/01/un-verano-de-combis-completas/

Vultures in Puerto Rico (2017). Hedge Clippers. Recuperado de http://hedgeclippers.org/roguesgallery-vultures-in-puerto-rico/

Williams, Eric (1994). Capitalism and Slavery. 1944. Chapel Hill: U of North Carolina P. 